
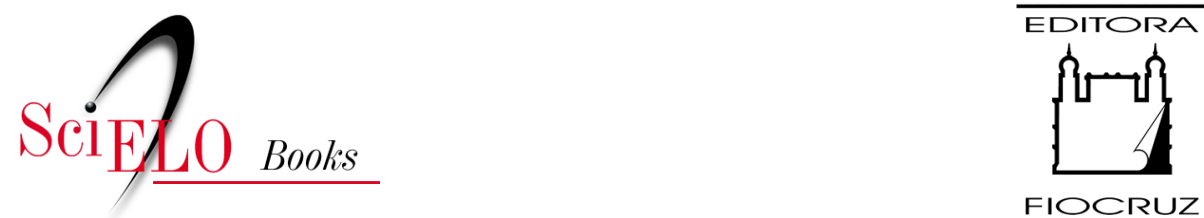

FIOCRUZ

\title{
2. A monarquia enfrenta a varíola na terra dos tupiniquins
}

\author{
Tania Maria Fernandes
}

\section{SciELO Books / SciELO Livros / SciELO Libros}

FERNANDES, T.M. A monarquia enfrenta a varíola na terra dos tupiniquins. In: Vacina Antivariólica: ciência, técnica e o poder dos homens, 1808-1920 [online]. 2nd ed. rev. Rio de Janeiro: Editora FIOCRUZ, 2010, pp. 43-64. ISBN: 978-65-5708-095-5. https://doi.org/10.7476/9786557080955.0003.

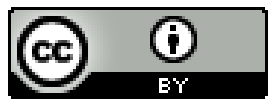

All the contents of this work, except where otherwise noted, is licensed under a Creative Commons Attribution 4.0 International license.

Todo o conteúdo deste trabalho, exceto quando houver ressalva, é publicado sob a licença Creative Commons Atribição 4.0.

Todo el contenido de esta obra, excepto donde se indique lo contrario, está bajo licencia de la licencia Creative Commons Reconocimento 4.0. 


\section{A Monarquia Enfrenta a Varíola na Terra dos Tupiniquins}

A chegada da Corte portuguesa ao Brasil significou para a escassa população brasileira - e também para os integrantes da própria Corte uma forte mudança nos âmbitos social, político e mesmo sanitário. As doenças infecciosas eram alguns dos problemas que tiveram de enfrentar. Entre estas, estava a varíola, cuja tentativa de controle foi uma das primeiras medidas sanitárias tomadas por D. João VI, por meio da criação da Junta Vacínica da Corte. Essa instituição, responsável pela vacinação jenneriana (humanizada), passou por diversas estruturações ao longo do governo imperial, associadas à formação do Estado imperial. Na esfera da saúde, o Estado começava a assumir responsabilidades antes consideradas de esfera privada. ${ }^{1}$

O processo de estruturação dos serviços de saúde, em especial aqueles vinculados à vacina antivariólica, e as discussões e alterações travadas no âmbito técnico-científico, tendo como agente central o Estado imperial, serão objeto de estudo neste capítulo. Para tanto, alertamos que as relações entre política institucional e conhecimento científico não se deram linearmente, mas de forma complexa e historicamente determinada. 


\section{Chegada da Corte: criação da Junta Vacínica}

A transferência da Corte portuguesa para o Brasil em 1808 impôs significativas alterações nas relações político-econômicas e no corpo social brasileiro, que viabilizariam a construção de um novo país, com anseios de 'civilização' e 'modernidade'. A transferência da Corte e a mudança para o Reino Unido de Portugal e Algarve foram decisivas para o processo de formação do Estado nacional brasileiro.

Quando a Corte portuguesa, composta por 15 mil pessoas, desembarcou em solo brasileiro, deu-se o primeiro grande passo para a independência da colônia. Ao abrir os portos às nações amigas, o próprio governo metropolitano promoveu a ruptura do pacto colonial, principal trunfo português para manter-se com algum poder diante das relações político-econômicas na Europa naquele início de século. O Brasil se transformava em grande mercado para os produtores europeus, principalmente para a Inglaterra, mantendo sua produção interna voltada estritamente para subsistência e agroexportação. Internamente, a chegada da Corte contribuiu para a independência por meio dos atos de D. João VI, que criou vários órgãos buscando alterar a visão colonial do país. Foi nesse contexto que se deu a criação da Junta Vacínica da Corte, que seria responsável pela difusão da vacina antivariólica no Reino. ${ }^{2}$

Sobre a cidade incidiram as principais medidas de transformação, que visavam a alterar seu perfil colonial. O Rio de Janeiro, que se transformou no principal centro de comércio e de decisões políticas, era também o espelho das precárias condições de vida e saúde do país, apresentando-se com um quadro de morbi-mortalidade que se colocava como um fator de impedimento ao processo de expansão econômica. ${ }^{3}$

O grande número de imigrantes que aqui desembarcavam e de navios que aportavam tinha de enfrentar um alto índice de doenças endêmicas e epidêmicas, que já estavam implantadas ou que se instalaram em razão do aumento repentino da população e das condições de vida com que se deparava o novo espaço urbano. Entre outras, a varíola era uma das principais moléstias que compunham o quadro de morbimortalidade nesse momento, atingindo indistintamente todas as camadas da população. Controlar a varíola no âmbito da sociedade como um todo significava, sobretudo, proteger os membros da Corte de uma doença encarada com grande pavor, altamente letal e 'asquerosa'. 
Em 1811, foi criada a Junta Vacínica da Corte, responsável pela vacinação antivariólica, que significou o início da implantação, no Brasil, da prática médica como ação estatal (Machado et al., 1978). A criação desse órgão seguiu a orientação assumida em países europeus, onde a vacinação ficou sob a responsabilidade de organizações criadas especificamente com esse fim, como o Instituto Vacínico Inglês e o Chambon de Paris, ou de outros órgãos já existentes, como no caso de Portugal, onde a Academia de Ciências ficou responsável pela difusão da vacina.

A organização dessas instituições relacionava-se à importância social e econômica assumida pela varíola, devido à sua relevância epidemiológica e à responsabilidade por grande parte dos expressivos surtos epidêmicos, que não distinguiam setores sociais para se manifestar.

A Academia Real das Ciências de Lisboa, referindo-se à criação da Junta Vacínica no Brasil, ressaltou a sensibilidade de D. João VI em relação à doença - por ter dois irmãos e um filho falecidos por agravamento da varíola, tornou-se um difusor da vacinação, na qual tinha plena confiança (Academia Real das Ciências de Lisboa, 1812). De fato, essa deve ter sido uma importante justificativa para a criação da Junta Vacínica, já que a varíola se infiltrava também na classe dirigente. Entretanto, também devem ser destacados fatores econômicos e políticos, principalmente o relacionamento com os países europeus, bastante significativo para a política traçada por D. João VI.

Sem dúvida, a Junta Vacínica simbolizou um dos primeiros passos de D. João VI com vistas a uma atuação no setor da saúde. Assumir a vacina antivariólica como prática estatal, embora não monopolizada pelo Estado, poderia significar uma possibilidade de maior eficácia no controle de uma doença que, além de seu impacto geral, atingia também a elite. Ao ser criada, a instituição vacínica subordinou-se à Fisicatura, único órgão existente responsável por uma parte do setor da saúde, que tinha como atribuição a fiscalização. Ampliando-se essa ação fiscalizadora, a Junta foi criada para, segundo a legislação, ser um "estabelecimento permanente, para que com mais extensão e regularidade se propague e se conserve, em benefício dos povos, o reconhecido preservativo da vacina" (Acervo do Arquivo Nacional).

O documento de criação da Junta, assinado por D. João VI, mencionava ainda que esta ocorreu "debaixo das vistas da Intendência Geral de Polícia e do Físico-mor do Reino". ${ }^{4}$ Assim, além da subordinação à Fisicatura, a Junta vinculava-se à Intendência Geral de Polícia, órgão 
fundamental para a efetivação das medidas propostas, incorporando, inclusive, entre seus funcionários, um oficial de polícia. ${ }^{5}$

Apesar do ambicioso projeto de D. João, a atuação da Junta foi muito inexpressiva diante da magnitude do problema da doença, tanto na capital como nas demais províncias, o que era constantemente ressaltado nas publicações oficiais.

A partir do fim da década de 1820 já se percebia a preocupação da Junta com o estabelecimento de um trabalho mais regular, ao menos no que dizia respeito ao mapeamento de suas ações. Mapas relativos à vacinação e relatórios de atividades passaram a ser formulados e apresentados a instâncias superiores de poder. Os mapas eram encaminhados ao ministro dos Negócios do Império em resposta a um 'Aviso' do mesmo ministro, solicitando a quantificação semestral das aplicações de vacina com a identificação dos grupos vacinados - "inocentes, adultos, escravos, masculino ou feminino".

Tal preocupação não se restringia a uma questão meramente técnica, específica da Junta. A década de 1820 trazia a perspectiva de constituição de um novo Estado Nacional, que, gradativamente, foi incorporando vários setores, que incluíam a medicina e as questões por ela suscitadas, visando à resolução de alguns problemas de âmbito social diretamente articulados com a organização do poder central e local.

A Constituição de 1824 e a Lei de 1828 estabeleceram a criação e as atribuições das câmaras municipais que existiriam, então, em todas as cidades e vilas regidas por um 'Código de Posturas'. Esses códigos, formulados pelas próprias câmaras, funcionavam como 'Leis Municipais', constituindo preceitos escritos que obrigavam os municípios a cumprir certos deveres que atendiam à manutenção da ordem pública (Neder et al., 1981: 33). Extinguiu-se a Fisicatura, e os exíguos serviços de saúde, vinculados a ela até então, passaram a se subordinar às câmaras municipais. Essa alteração não trouxe, de fato, mudança substancial aos serviços, e atendia, na realidade, à proposta de descentralização do poder estatal em função da consolidação das relações locais regidas pela ascendente 'classe senhorial' (Mattos, 1987). Esse processo, associado às iniciativas particulares de vacinação jenneriana no âmbito das localidades, forçou a criação de instituições que se voltavam para a tentativa de controle da varíola em nível local. 
No município do Rio de Janeiro, o Código de Posturas, elaborado em 1832, estabeleceu pela primeira vez no Brasil a obrigatoriedade da vacina, indicando que:

toda pessoa do termo da cidade que tiver a seu cargo a educação de alguma criança de qualquer cor que seja, será obrigada a mandá-la à casa da vacina para ser vacinada, até pegar ou fazê-la vacinar em casa, podendo-o dentro de três meses de seu nascimento, e de um, depois que tiver a seu cargo, passando desta idade e estando com saúde para receber o remédio. Os que se acharem em contravenção serão multados em 6 \$. As criadeiras encarregadas da criação dos expostos são também compreendidas nesta disposição, levando-os ao depósito da Santa Casa para este fim. (Acervo do Arquivo Nacional)

Dessa forma, pela primeira vez, no Brasil, normatizava-se o uso da vacinação, tornando-a obrigatória e passível de multa.

Apesar de obrigatória para uma fração delimitada da população, a vacinação não se fez cumprir. A única obrigatoriedade cumprida era aquela ditada pela escravidão nas fazendas, para onde o vacinador era deslocado por solicitação dos proprietários de escravos, o que alcançava cerca de $40 \%$ da vacinação em relação aos demais vacinados (Acervo do Arquivo Nacional). No âmbito da população em geral, o uso da vacina era muito desacreditado e temido, como afirmam os responsáveis pela vacinação e estudiosos do assunto em vários ofícios e publicações específicas (Guarany, 1863; Lee, 1863; Moreira, 1862).

Ao longo do governo imperial, começaram a ter participação os profissionais liberais, compondo a nova elite política que, por tradição, era até então constituída de juristas (Carvalho, 1980; Mattos, 1987). ${ }^{6}$ Entre esses novos membros, incluíam-se os médicos, que foram sendo incorporados à organização estatal dos serviços de saúde. Além disso, começaram também a participar da condução política dos serviços de saúde a Sociedade de Medicina do Rio de Janeiro, criada em 1829 e transformada posteriormente em Academia Imperial de Medicina, e as faculdades de medicina, reconhecidas pelo governo como órgãos consultivos dos poderes públicos, sendo constantemente chamadas a dar pareceres sobre questões relevantes no âmbito da saúde (Edler, Ferreira \& Santos, 1990; Kury, 1990).

A participação da Academia de Medicina e das faculdades como órgãos consultivos do governo pode ser percebida, por exemplo, na década de 1830, durante a epidemia de varíola que atingiu o Rio de Janeiro. Nessa ocasião, foram solicitados pareceres sobre as medidas a serem 
tomadas para debelar o surto epidêmico, principalmente quanto à questão da revacinação antivariólica, apontada como uma das medidas para o controle de epidemias. Essa questão gerou intenso debate no meio médico e político, não havendo nenhuma opinião comprovada cientificamente sobre a necessidade de uma segunda dose, o que era visto por alguns como uma forma de atestar a imunidade e por outros como uma dose de reforço.

A Faculdade de Medicina da Bahia, afirmando que "o estado atual da ciência não permite resolver satisfatoriamente nem pela afirmativa nem pela negativa", julgou desnecessária a revacinação, com base no parecer de dois 'facultativos' responsáveis pela vacinação em Salvador. Aconselhava, no entanto, a aplicação em segunda dose para os casos em que ficasse comprovada falha na primeira. Ainda segundo o parecer dessa faculdade, a revacinação podia ser prejudicial, "podendo desenvolver-se uma pústula ou vacina falsa, e que sem a virtude preservadora poderão operadores pouco expertos propagar esta vacina nos indivíduos não vacinados". ${ }^{7} \mathrm{O}$ inspetor da Junta Vacínica da Corte, Hércules Otaviano Muzzi, baseando-se em Jenner e em 'sua longa prática', fundamentou também opinião contrária à revacinação. Para ele, “os indivíduos que foram uma vez bem vacinados estão garantidos da variolosa e se alguns têm sido atacados provém isso de se haver tomado a vacina espúria pela verdadeira". Assim, aconselhava a revacinação somente para os casos em que havia dúvidas sobre a eficácia da vacina aplicada (Acervo do Arquivo Nacional). ${ }^{8}$

A Academia Imperial de Medicina, por sua vez, por intermédio de uma comissão organizada para esse fim, julgou ser necessário, para fundamentar um parecer nesse sentido, constituir uma equipe de trabalho que realizasse uma investigação prática e que, guiada pela própria experiência, pudesse "com maior solidez fundamentar a sua opinião" (Acervo do Arquivo Nacional, 1839).

A revacinação e outros pontos referentes à produção da vacina vinham tomando corpo nos institutos europeus, tendo, em geral, como referência a perda do poder imunizante. No Brasil, com base nos pareceres anteriormente relatados, percebe-se que a revacinação ainda era entendida como uma forma de comprovação da imunidade e não como dose de reforço, como se discutia em outros países. No âmbito das instituições nacionais, a discussão não refletia as afirmativas já formuladas nos estudos europeus que previam a perda do poder imunizante em 
vacinações 'verdadeiras' -, isto é, não levava em conta as indicações de que a vacinação não garantia imunização para toda a vida. Daí a indicação de revacinação (como reforço), ao contrário da orientação de 'revacinação' de Jenner, de que se deveria aplicar nova vacina em caso de dúvida.

Assim como ocorria com a vacinação, muitos grupos médicos se opunham à segunda dose, fosse ela para reforço ou para comprovação da imunidade. A oposição à revacinação - e mesmo à vacinação - era pautada por preocupações que ultrapassavam a justificativa estritamente técnica e se detinham, também, nos âmbitos político e moral.

Como se pode perceber, não havia consenso entre os médicos quanto à medida a ser adotada, o que aumentava ainda mais a dificuldade do Estado em assumir uma posição.

A questão continuou em pauta no Brasil, verificando-se discussões sobre o assunto mesmo depois de elucidado com as experiências nos países europeus na década de 1850. Soeiro Guarany, por exemplo, em trabalho apresentado à Academia de Medicina para disputar o lugar de membro titular, argumentava que a revacinação tinha importância fundamental. Apresentava como base para suas afirmativas a prática e as experiências realizadas em países como França e Alemanha, onde a revacinação já era indicada para um período de 10 a 12 anos e sempre que se localizassem epidemias da doença. Esse trabalho provocou certo impacto e assegurou a seu autor um lugar na Academia e a publicação, posterior, de seu estudo no periódico Gazeta Médica do Rio de Janeiro (Guarany, 1863: 490).

\section{Anos 40: \\ a vacina nos planos de centralização}

O período que se iniciou em 1840 apresentou mudanças do ponto de vista da ação estatal em relação às medidas sanitárias vigentes, forçadas pelas exigências de uma resposta política às epidemias de varíola e febre amarela. ${ }^{9}$ As propostas, que visavam à centralização das ações, criaram um clima de tensão com o poder local, amenizado por medidas conciliatórias implantadas estrategicamente por D. Pedro II e que conquistaram apoio mesmo das oligarquias, atingidas diretamente com as medidas centralizadoras (Carvalho, 1988). 
Apesar do apoio conquistado pelo governante, esse conflito certamente dificultou a ação estatal com relação às medidas sanitárias, em particular as que se referiam à vacinação, uma vez que propunham controlar o nível local a partir de orientações do governo central. O Instituto Vacínico do Império, criado em 1846, e a Junta de Higiene Pública, em 1850, representavam uma tentativa de centralização dos serviços de saúde, buscando, quanto à vacinação antivariólica, regulamentar sua prática, incorporando a reordenação político-administrativa, em processo no interior do próprio Estado, e a nova proposta traçada para a medicina.

Ao contrário da Fisicatura, voltada estritamente para a fiscalização, as organizações criadas a partir de 1840 calcavam-se nos conhecimentos da higiene e atuavam diretamente no campo médico e não somente no exercício de fiscalização da medicina. A racionalidade administrativa, que começava a ser incorporada, buscaria também introduzir, ideologicamente, a ação de controle sanitário - antes incumbência da Polícia por meio da articulação entre Fisicatura e Intendência Geral de Polícia.

Apesar das mudanças verificadas na estrutura organizacional com a criação da Junta de Higiene Pública e do Instituto Vacínico, percebe-se ainda uma atuação muito restrita do poder público no campo da saúde, eminentemente voltada para os surtos epidêmicos que surgiram de forma mais intensa a partir de 1850. Essa constatação pode ser verificada quando se analisa o orçamento imperial. O gasto normal com a saúde pública era inteiramente aplicado no saneamento e na assistência à saúde na Corte, e dirigido nas províncias somente para a Inspetoria de Saúde dos Portos, órgão que exercia, nesses locais, a fiscalização sanitária (Carvalho, 1988).

Nesse momento, o governo imperial recorreu à mesma estratégia utilizada na década de 1830 diante da epidemia de varíola: solicitou às várias instituições ligadas à saúde pública que formulassem uma proposta para reestruturar os serviços de vacinação, o que deu origem ao Instituto Vacínico.

A maioria das propostas formuladas visava a estabelecer um regimento que atendesse a todo o Império, criando uma rede de juntas provinciais. ${ }^{10}$

Em decorrência desse processo, em agosto de 1846 foi criado o Instituto Vacínico do Império. O Artigo $1^{\circ}$ do decreto de criação do Instituto estabeleceu que este seria composto por: um inspetor-geral; uma junta vacínica na capital do Império; um comissário vacinador provincial na capital de cada província; e comissários vacinadores paroquiais. Por 
esse decreto, o órgão de vacinação da Corte atuaria sobre todas as províncias do Império, como um órgão central que dita normas e fiscaliza a atuação nas demais localidades. A Junta Vacínica, subordinada ao Instituto Vacínico, passaria a ser um órgão consultor e responsável pela vacinação na Corte, sendo composta pelo inspetor-geral que a presidiria, quatro vacinadores efetivos, dois supranumerários, um secretário e um porteiro, todos com vencimentos correspondentes às suas atribuiçóes e estabilidade no emprego como servidores do governo. Para os comissários paroquiais e municipais, no entanto, não se previa remuneração pelos serviços de vacinação, ficando a cargo das municipalidades estabelecer uma forma de pagamento, determinada no âmbito do município. Entre as atribuições da Junta Vacínica, constava a realização de reuniões que ocorreriam "todos os domingos e mais uma vez ao menos na semana", quando se procederia também à vacinação. Nessas reuniões, seriam discutidas questões pertinentes à vacinação.

A reforma de 1846 seguia os parâmetros político-administrativos do Segundo Reinado, determinando a centralização dos serviços nas mãos do governo imperial e atribuindo às localidades a responsabilidade pela execução e financiamento desses serviços. Quanto à vacinação, caberia ao governo central a coordenação e fiscalização dos serviços a serem executados nas províncias, custeados pelos cofres municipais, o que, certamente, contribuiu para inviabilizar a efetivação desses serviços.

A mesma legislação que criava o Instituto Vacínico do Império definia, mais uma vez, a obrigatoriedade da vacinação em crianças de até três meses e em grupos determinados. Exigia-se atestado de vacinação ou comprovação da doença para admissão no Exército ou Armada, em estabelecimentos de educação ou oficinas a cargo do governo. A mesma exigência era feita para os admitidos, matriculados ou inscritos em qualquer estabelecimento oficial, literário, público ou particular.

A obrigatoriedade da vacina era, em geral, defendida pelos adeptos desse meio profilático contra a varíola. Alguns deles sugeriam, até mesmo, a participação da polícia para a garantia da execução da lei (Guarany, 1863: 460). A revacinação, que vinha tendo sua validade discutida desde a década anterior, foi assumida como orientação técnica para ser aplicada em um período de três anos após a implantação do Regulamento, funcionando como experimentação para que a Junta pudesse adotar uma posição segura. Dessa forma, a revacinação ainda estava distante de ser aceita, mesmo pelos legisladores. 
Trazia, ainda, uma preocupação quanto aos avanços científicos promovidos nos países europeus. Era de competência de a Junta manter-se atualizada por meio de contatos com instituições de outros países, buscando o aprimoramento técnico para a produção da vacina, já que o Brasil ainda não se detinha em pesquisas experimentais nesse campo, restringindo-se à reprodução das técnicas desenvolvidas na Europa.

Em virtude de a vacina animal não ter chegado ainda ao Brasil, o Decreto de 1846 acrescentava que

a pessoa que conseguir regenerar o vírus vacínico descobrindo a varíola das vacas (cow-pox) ou inoculando o fluido vacínico em animais obterá um prêmio (de triplicado valor no primeiro caso) depois que se tiver reconhecido por todos os meios a verdade daquele descobrimento ou inoculação. Estes prêmios serão conferidos enquanto a necessidade reclamar este incentivo.

Várias foram as tentativas com relação a este último artigo, porém, somente em 1887 essa vacina aqui chegou. Então, tal artigo da legislação não vigorava mais, e várias mudanças administrativas já delimitavam um novo perfil para as instituições de higiene.

Em 1849, o visconde de Monte Alegre, ministro do Império, ressaltou as dificuldades no cumprimento dos serviços do Instituto Vacínico, afirmando que era urgente a elaboração de

regulamentos sanitários que auxiliassem, desenvolvessem e completassem o pensamento que presidira a fundação do Instituto Vacínico, dando as disposições por que se regia, o vigor de que necessitavam para que o povo se não subtraísse à vacinação e se removessem outras causas de contágio por meio de medidas coercitivas e providências apropriadas que deviam ser consignadas naqueles regulamentos. (Barbosa, 1908: 425)

Além desse documento oficial, há várias outras referências à necessidade de estabelecer instrumentos 'eficazes' para fazer cumprir as normas sanitárias determinadas, principalmente quanto à vacinação. Tais instrumentos referiam-se a formas jurídicas de fazer cumprir a lei de obrigatoriedade da vacina, por meio de medidas coercitivas.

Ainda no fim da década de 1840 foram tomadas novas medidas, visando, mais uma vez, à restruturação dos serviços de saúde. A Junta de Higiene, criada em 1849, foi inicialmente proposta para o controle da febre amarela, porém teve suas atividades ampliadas com a incorporação do Instituto Vacínico e da Inspeção de Saúde dos Portos, passando a denominar-se Junta Central de Higiene Pública em 1851. 
As medidas e orientações políticas formuladas e regulamentadas nesse momento, apesar de se manterem válidas até 1880, não alteraram significativamente o quadro nosológico do Rio de Janeiro nem de outras regiões do país. Ao contrário, no que diz respeito à varíola, há referências de aumento considerável de casos, inclusive de pessoas já vacinadas, o que viria fortalecer o questionamento da eficiência da vacina, defendida por alguns como a mais completa medida profilática e tida, por outros, como a mais despótica prática médica. Os dados estatísticos que possibilitariam uma análise mais profunda eram, ainda, bastante esparsos e pouco confiáveis. A Junta de Higiene deu início, a partir de 1860, à organização desses dados, mas somente em 1890 foi publicado o $1^{\circ}$ Anuário Estatístico Demógrafo Sanitário (Barbosa, 1908). ${ }^{11}$

Em 1880, o barão do Lavradio, que ocupava os cargos de presidente da Junta de Higiene e de inspetor-geral do Instituto Vacínico, afirmou, em seu Relatório de Trabalho, que

os serviços de vacinação têm tido resultado de um modo pouco profícuo, como sucede sempre entre nós, por causas numerosas, entre as quais sobressaem, de um lado, a indiferença com que a nossa população olha para os efeitos de sua aplicação e só buscando o auxílio que ele lhe oferece para livrá-la do terrível flagelo da varíola ao surgir alguma epidemia devastadora; de outro lado, os preceitos que atuam no espírito dos habitantes do interior de todas as províncias, encarando-a como meio de transmissão e desenvolvimento da varíola. (Barbosa, 1908: 427)

Respondendo às observações do inspetor do Instituto Vacínico, Plácido Barbosa destacou que "com a organização do serviço que então vigorava era impossível alcançar melhores resultados." Acrescentou, ainda, que o governo, apesar desse quadro, nunca se animou a reformar o serviço vacínico, que permanecia com as mesmas orientações de 1846, mas não funcionava sequer segundo aqueles parâmetros de estruturação (Barbosa, 1908).

Ressaltava-se, ainda, a qualidade da linfa aqui produzida como causa de ineficiência da vacinação antivariólica, o que o barão do Lavradio tentou resolver regularizando a importação de linfa vacínica dos países europeus, principalmente do Instituto Jenneriano, na Inglaterra. A importação da linfa também era condenada, criticando-se as condições de conservação da linfa importada e o dispêndio para os cofres do governo.

Nesse contexto de críticas à eficácia da vacina, houve algumas tentativas oficiais para a produção da vacina animal no Brasil. Em 1884, o 
governo imperial resolveu incumbir a recém-criada Escola Veterinária de Pelotas do estudo e possível cultivo da vacina em vitelos, organizando para isso, junto à Escola, um Instituto Vacínico. Tanto a Escola de Pelotas quanto o Instituto ficariam sob a direção do dr. Rebourgeon, que se responsabilizaria pelos experimentos. Dois anos depois, constatada a ineficácia desse serviço e a má qualidade da vacina aí produzida, o governo cessou seu custeio e retirou o material que havia adquirido para esse fim, remetendo-o à recém-criada Inspetoria Geral de Higiene.

Com a criação dessa Inspetoria, em 1886, foram extintos a Junta Central de Higiene e o Instituto Vacínico, cujas atribuições foram incorporadas às competências da Inspetoria. A vacinação antivariólica ficou sob a responsabilidade direta da Inspetoria Geral de Higiene e das inspetorias das províncias, acarretando uma desestruturação dos parcos serviços existentes. Ao longo desse ano, verificou-se um aumento considerável do número de casos de varíola na capital, que, no mês de julho, chegou a vinte mortes por dia. Apesar do grave quadro instalado, a Inspetoria não o assumiu como um surto epidêmico, afirmando em seu Relatório de Atividades Anuais que "não chegou a tomar a forma de uma epidemia franca". Esse relatório apontava o uso da revacinação e a necessidade de implantar a vacina animal como questões fundamentais para um trabalho que garantisse a eficácia da vacina e o controle da doença, porém sem assumir nenhuma proposta concreta de trabalho. Quanto aos trabalhos de vacinação realizados em 1886, o Relatório da Inspetoria revela que estes "não atenderam às necessidades de popularizar este meio preventivo da varíola”, acusando os médicos de atuar negativamente no processo de aceitação da vacina por parte da população, uma vez que não a indicavam como profilático (Relatório da Inspetoria Geral de Higiene, 1887).

No decorrer de 1887 , a varíola alcançou a taxa de $47 \%$ no obituário do Rio de Janeiro, superando inclusive o índice de mortalidade por tuberculose, o que gerou intensas críticas dirigidas à Inspetoria, por não tomar providências para impedir que a varíola assumisse proporções epidêmicas. O Brazil Médico - importante periódico da época - manifestou-se afirmando que

apesar da sua gravidade e da facilidade ou possibilidade de desenvolver-se epidemicamente, não consta em documento algum oficial que se tivesse procurado prevenir o mal (...) Se desde os primeiros casos observados se tivessem empregado os meios profiláticos 
próprios, teríamos, sem dúvida, circunscrito e extinto o germe epidêmico (Brazil Médico, 1887a).

A única proposta da Inspetoria para controlar a epidemia, ainda segundo o Brazil Médico, foi formulada seis meses após iniciado o processo epidêmico, com a solicitação, ao ministro do Interior, de que se montassem pequenos hospitais de isolamento nos subúrbios da capital. Essa proposta levou a uma discussão sobre o melhor meio profilático a ser utilizado em épocas de epidemia. A desinfecção, o isolamento nosocomial e a vacinação geravam polêmica, sendo a hospitalização defendida por alguns somente para o início do surto. Além das questões habitualmente apontadas com referência à vacinação e à revacinação, havia dúvidas quanto à inoculação da vacina em pessoas com grande possibilidade de já estarem infectadas devido à disseminação do vírus no período epidêmico. Afirmava-se que, nesses casos, a reação vacínica era intensa, e quem chegasse a contrair a doença a teria também de forma agravada (Brazil Médico, 1887b, c).

$\mathrm{Na}$ realidade, com a criação da Inspetoria Geral de Higiene, em 1886,e a extinção do Instituto Vacínico do Império, na mesma ocasião, além do fracasso do Instituto de Pelotas na tentativa de introduzir a vacina animal no país, a vacinação antivariólica já havia sido praticamente desativada, o que possibilitou a instalação do quadro epidêmico na extensão com que foi constatado.

Em termos de propagação da varíola nos estados brasileiros, destaca-se a situação do Ceará - agravada pela seca. O período de 1888-1890 foi marcado por forte seca, que ocasionou o recrudescimento violento da varíola, reproduzindo o quadro catastrófico de 1878 naquele estado, quando a varíola chegou a matar mais de mil pessoas em um só dia na cidade de Fortaleza (Anais da Faculdade Nacional de Farmácia, 19521954).

\section{Vacina Antivariólica Animal: ação de iniciativa particular}

O ano de 1887, além de ser marcado por um sério surto epidêmico na cidade do Rio de Janeiro, assistiu a um significativo acontecimento, que deu uma nova feição à ação antivariólica no Brasil. A vacina cultivada e extraída de vitelos, conhecida como vacina animal, conseguiu ser 
produzida no país por iniciativa particular do médico Pedro Affonso Franco. Esse novo profilático antivariólico, que já se desenvolvia plenamente na Europa desde meados do século, mostrando-se de maior eficiência do que a vacina jenneriana, ainda não havia alcançado o território brasileiro.

O Brasil do século XIX era um país eminentemente importador de produtos e exportador de matérias-primas. Entre as importações, incluía-se também o 'conhecimento científico', que, nesse momento, tinha nos modelos europeus suas principais referências na área da saúde. Algumas atualizações chegavam aqui não como idéias que estariam sendo experimentadas, mas, sim, como técnicas que seriam trazidas e implantadas. O método científico de base experimental aplicado à medicina teria sua consolidação no Brasil somente a partir dos últimos anos do século XIX e início do século XX.

O médico Pedro Affonso Franco, detentor do título nobiliárquico de barão de Pedro Affonso e que ocupava um cargo de direção na Santa Casa da Misericórdia, solicitou ao Instituto Chambon de Paris amostra da vacina que "desta vez conseguiu chegar viável ao Brasil", ao contrário de outras tentativas feitas por ele anteriormente. Esse mesmo médico, que tinha constante preocupação com a introdução de técnicas médicas no país, já havia solicitado da Europa amostra vacinal que, por várias vezes, fora enviada, mas não obtivera sucesso em tentativas de inoculação em vitelos. Pedro Affonso afirmava que essas tentativas de inoculação em vitelos teriam "abortado por causa da demora na transmissão, da Europa para o Brasil, em longa viagem de cerca de 21 dias e dos tubos de linfa que talvez não tivessem partido de lá em estado de frescura suficiente" (Franco, 1888: 44). A descrição dessas experiências - realizadas no estábulo do fornecedor de leite do hospital - consta do relatório apresentado em 1878 à Provedoria da Santa Casa da Misericórdia. ${ }^{12}$

A amostra a partir da qual o barão inoculou vitelos e conseguiu reproduzir a vacina proveio da França, segundo ele "sob condições seguras, que resguardaram sua atividade" (Franco, 1888: 44). A supervisão do processamento da amostra ficou a cargo do médico Augusto Ferreira dos Santos, diretor do Serviço Sanitário da Santa Casa da Misericórdia, que, por indicação do governo imperial, se aprimorava na Europa no estudo da profilaxia da raiva. Ele acompanhou todo o processo de inoculação, extração e acondicionamento da amostra vacinal, seguindo as instruções de Pedro Affonso, o que pôde, segundo ele, garantir a 
qualidade da vacina. A amostra, enviada sob os cuidados de assepsia e conservação indicados na época, chegou ao Rio de Janeiro em 23 de julho, sendo, no mesmo dia, inoculada em vitelos, no matadouro do Hospital da Santa Casa da Misericórdia (Franco, 1888).

Com essa conquista iniciou-se um novo processo no país - tanto técnico-científico como administrativo - com relação à vacina antivariólica. Além da introdução da vacina animal, de eficácia superior à da humanizada, a responsabilidade por sua produção e aplicação foi transferida da esfera governamental para a iniciativa particular. A prática da vacina humanizada, difundida desde o século XIX no Brasil, apesar de ser assumida oficialmente pelo Estado, era também realizada por médicos como iniciativa individual e particular, porém em pequena escala, não produzindo efeito significativo sobre o quadro epidemiológico.

A partir da tentativa vitoriosa de Pedro Affonso com relação à vacina animal e do estabelecimento de contratos entre ele e o governo da União e do município, esta prática passou, no Distrito Federal, a ser assumida como iniciativa particular, subvencionada e fiscalizada pelo Estado, com características muito singulares no que diz respeito ao seu formato jurídico.

Com a aprovação do barão de Cotegipe, provedor da Santa Casa da Misericórdia, Pedro Affonso procedeu às primeiras vacinações na instituição no dia 4 de agosto de 1887. A primeira sessão dedicada à aplicação da vacina de origem animal ocorreu após anúncio nos jornais. Foram inoculadas 12 crianças, das quais seis eram meninas recolhidas no Hospital da Santa Casa. Os demais foram levados por seus responsáveis, por meio de convite ou atraídos pelo anúncio dos jornais. Já que o sucesso com as 'cobaias infantis' estava comprovado, a segunda série de vacinados incluía indivíduos adultos. Aos poucos, as sessões de vacinação foram-se incorporando à rotina da Santa Casa.

Seguindo a lógica que permeava a ação filantrópica, nesse momento, não caberia a Pedro Affonso receber remuneração por essa prática. Ele declarou que "não aceitava remuneração alguma por todo o trabalho de vacina, quer feito na Santa Casa, quer em domicílios das pessoas que não pudessem ali concorrer, quer do fornecimento de tubos e placas para fora da Corte" (Jornal do Commercio, 13/10/1887). Passou, mais adiante, a receber subvenções do Estado para o fornecimento da vacina, ressaltando, insistentemente, que tal verba era direcionada ao custeio de sua produção, não lhe cabendo nenhuma retribuição monetária. Apesar 
de Pedro Affonso negar as possíveis vantagens advindas da subvenção estatal, acreditamos que ela conferia não apenas prestígio a quem dela se beneficiava. Nesse caso, não podemos descartar a existência de algum lucro financeiro, como, por exemplo, aquele oriundo do aluguel das propriedades de Pedro Affonso, onde mais tarde foram instalados o Instituto Vacínico e o estábulo para a produção da vacina. ${ }^{13}$

A relação estabelecida entre o governo e Pedro Affonso constituía um vínculo que não se caracterizava propriamente como filantrópico, assemelhando-se ao formato de uma concessão pública, na qual o Estado financia um empreendimento particular que não é incorporado como estabelecimento estatal, de acordo com o próprio entendimento de Pedro Affonso (Instituto Vacínico Municipal. Relatório, 1915).

Pedro Affonso, nesse momento, significou para o Estado a solução de um importante problema, devido à dificuldade de organizar, na esfera governamental, uma instituição responsável por uma questão ainda geradora de intensa polêmica, como era o caso da vacina antivariólica. A dificuldade do Estado em enfrentar as questões que circundavam a vacina - vacinação, revacinação e obrigatoriedade da vacina - denotava, na realidade, uma falta de vontade política de intervir nos problemas da saúde pública. O governo imperial, apesar das tentativas de intervenção, com a criação dos órgãos antes aqui apontados, carecia de apoio político por parte do poder local e de assessoramento dos médicos, que expressavam divergências sobre essas questões.

Tendo Pedro Affonso assumido o serviço de vacinação, o Estado se desincumbiu diretamente da tarefa, retomando-a apenas em 1920, com a reforma dos serviços de saúde, que criou o Departamento Nacional de Saúde Pública. Subsidiado inicialmente pelo governo imperial, depois pelo governo republicano e mais tarde pela municipalidade, Pedro Affonso se responsabilizou até a década de 20 pela produção da vacina antivariólica no Distrito Federal e em algumas províncias.

\section{O Barão de Pedro Affonso e suas Primeiras Estratégias}

A magnitude do surto de varíola que acometeu a cidade do Rio de Janeiro em 1887 exigia do governo uma atitude mais concreta quanto à vacinação. Esse fato fortaleceu a posição de Pedro Affonso, que vinha desenvolvendo suas experiências na Santa Casa ainda de forma tímida. 
Assim, sua ambição de criar um Instituto Vacínico ia ao encontro da necessidade do governo de resolver um problema agravado ao se terem desativado os órgãos responsáveis, até então, pela vacinação.

Pedro Affonso Franco, cujo nome de família era Pedro Affonso de Carvalho, substituído após desavença com o pai, era reconhecido por seus biógrafos como figura de destaque no meio científico e na sociedade carioca, tendo sido, inclusive, médico do presidente Prudente de Moraes. ${ }^{14}$ No Brasil Império, recebeu o título de Oficial da Ordem da Rosa e adquiriu o título de barão em 31 de agosto de 1889, segundo ele, para satisfazer o desejo de ascensão social de sua segunda esposa, Margarida Toledo.

Médico-cirurgião, nascido em 1845 no interior do Rio de Janeiro, formou-se na Faculdade de Medicina do Rio de Janeiro em 1869, defendendo a tese de doutoramento Idéias Gerais sobre o Estreitamento da Uretra. Logo após, prosseguiu seus estudos na Universidade de Paris, onde obteve o título de doutoramento em 1871, desenvolvendo uma tese sobre o mesmo assunto. Regressando ao Rio de Janeiro, dedicou-se à clínica médica e ingressou em 1872, por concurso, na vaga de opositor da seção cirúrgica na Faculdade de Medicina do Rio de Janeiro. Mais tarde, tornou-se catedrático de patologia externa, jubilando-se em 1891. Apesar de sua rápida passagem pela Faculdade, chegou a diretor interino da instituição. Incorporou-se à Santa Casa, onde ocupou cargos de direção por muitos anos. Assumiu, ainda, nos últimos anos do século XIX, a direção dos serviços de saúde pública municipal. Pedro Affonso pode ser caracterizado como um médico interessado em inovações científicas, como prova o esforço que realizou para trazer a vacina animal para o Brasil.

Ao longo de sua trajetória profissional, demonstrou incrível habilidade política ao estabelecer uma rede de relações que o manteve como figura proeminente no campo da saúde pública. Enquanto foi responsável pela produção da vacina antivariólica (1887-1919), usou a tática de estabelecer contatos com políticos e médicos ilustres e influentes, buscando apoio para a manutenção de seu trabalho. Como parte de sua estratégia de consolidação da vacina animal, o barão buscou, de diversas formas, ampliar a aceitação dessa vacina como método profilático antivariólico, divulgandoa e promovendo discussões na Câmara Municipal, na grande imprensa, em espaços acadêmicos e em órgãos governamentais. 
Na Câmara Municipal da Corte, uma de suas primeiras incursões foi solicitar, por carta ao presidente, a dispensa do imposto de circulação, no espaço urbano, do gado utilizado para vacinação. Foi aprovada por unanimidade uma proposta encaminhada por J. do Patrocínio, com adendo do dr. Nobre, segundo a qual

a Câmara Municipal despenda pela verba eventuais a quantia necessária para que sejam facilitados ao dr. Pedro Affonso Franco, como a todos os outros médicos que quiserem prestar o relevante serviço da vacina animal, todos os meios imprescindíveis para tal fim de acordo com a Inspetoria Geral de Higiene. (Acervo da Casa de Oswaldo Cruz, recorte de jornal, data provável de 25/8/1887)

A liberação do imposto para a circulação dos vitelos utilizados na produção da vacina foi facilmente aprovada, compondo o quadro de relações em que o governo imperial buscava incentivar as iniciativas particulares com relação à vacina antivariólica, indicada claramente na legislação de 1846, ao oferecer um prêmio àquele que conseguisse implantar a vacina animal no país.

Ainda em razão da busca de apoio à vacina animal, identificamos outro passo de Pedro Affonso, ao solicitar da Inspetoria de Higiene, em setembro de 1887, que esta "mandasse verificar os resultados da vacinação animal e que decidisse se seria este método ou não conveniente para o melhoramento da linfa empregada nas vacinações públicas" (Jornal do Commercio, 13/10/1887, artigo assinado pelo barão de Pedro Affonso).

O barão de Ibituruna, inspetor-geral de Higiene, formou uma comissão, composta por Bento Gonçalves Cruz e Francisco Marques de Araújo Góes, para avaliar a vacina animal produzida por Pedro Affonso. Ela foi aprovada em relatório apresentado em sessão da Diretoria de Higiene de 11 de janeiro de 1888 (Franco, 1888: 91).15

O relatório elaborado pela comissão, no entanto, era ambíguo quanto ao apoio à vacina animal produzida por Pedro Affonso, embora tenha sido incorporado como veiculador de uma avaliação extremamente positiva. Mesmo reconhecendo-se sua importância em outros países e a qualidade da vacina apresentada, no relatório recomendou-se a manutenção da vacina humanizada paralelamente à vacina animal, ressaltando-se a aceitação que aquela já havia conquistado junto à população, apesar de reconhecer seus problemas técnicos. ${ }^{16}$ Com relação ao cumprimento da Lei da Obrigatoriedade da Vacina, o relatório acrescentava que era necessário reorganizar o serviço de vacinação "de modo a inspirar inteira confiança 
aos interessados", defendendo ainda a utilização de métodos persuasivos ao invés dos coercitivos, para convencer os indivíduos a usar a vacina.

Logo após as primeiras inoculações da vacina, entre o fim de setembro e os últimos dias de outubro de 1887, Pedro Affonso publicou cerca de vinte artigos no Jornal do Commercio, nos quais abordava o tema 'vacina' desde as práticas anteriores à descoberta de Jenner até as primeiras inoculações da vacina animal no Brasil. Ele justificou a publicação desses artigos com base no seu "desejo de vulgarizar (...) os conhecimentos de modo a habilitar a todos a formar por si juízo sobre a vacina e sua utilidade", procurando "destruir os preconceitos e combater as afirmações da seita antivacínica”. É interessante observar a reação de certos médicos diante dessa atitude do barão. Em artigo publicado no Brazil Médico, J. Monteiro defendeu a idéia de que esse assunto deveria ser reservado a especialistas, expressando uma atitude corporativa em relação à categoria médica e a seu conhecimento científico (Monteiro, 1887b).

Em 1888, os artigos redigidos por Pedro Affonso foram reunidos em um livro, que incluía os resultados de um inquérito sobre a vacinação, realizado por ele, entre alguns representantes da categoria médica que Pedro Affonso caracterizava como a "elite da classe médica do Rio de Janeiro". Os principais depoimentos foram assinados por barão de Torres Homem, barão do Lavradio, Ferreira dos Santos, Cypriano de Abreu, Hilário de Gouveia e Barata Ribeiro, que descreveram suas experiências clínicas em relação à vacinação e elogiaram a iniciativa de Pedro Affonso. Como o próprio Pedro Affonso reconhecia, sua intenção era buscar legitimidade junto a seus pares, declarando que tinha a "sanção da autoridade, da ciência e da ilustração" daqueles médicos a quem se referia também como "os príncipes da medicina do Império" (Franco, 1888: 71).

Entre as reações contra Pedro Affonso no período em que esses artigos foram publicados, destaca-se a polêmica travada pelo médico Álvaro Alberto, que publicou, por meio da imprensa, duras críticas a Pedro Affonso. Ele contestava, principalmente, as afirmativas em defesa da vacina animal, destacando as que diziam respeito à impossibilidade de transmissão de doenças típicas dos bovinos através da vacina. Acompanhando as publicações de Pedro Affonso, esse médico elaborou suas críticas e defendeu a vacina humanizada como a forma mais pura de proceder à vacinação (Acervo da Casa de Oswaldo Cruz, recortes de jornal).

No início de 1888, Pedro Affonso encaminhou duas propostas ao governo do Império para que este subvencionasse o serviço de vacinação 
sob sua responsabilidade, aproveitando, assim, a conjuntura favorável decorrente do surto recente de varíola na capital. Com essa iniciativa, desencadeou um processo de negociação política que viabilizou a criação, alguns anos mais tarde, do Instituto Vacínico Municipal.

Na primeira proposta, solicitava do governo uma participação nos gastos com a construção de um prédio, além da verba de manutenção do serviço. Na segunda, liberava o governo dos custos com a construção e montagem, requisitando apenas que este financiasse a manutenção do Instituto com a mesma quantia estipulada na proposta inicial. Sugeria a indicação do médico Henrique Dodsworth - especializado na Europa em cultura de vacina animal - para dirigir o estabelecimento e acrescentava que não estaria vinculando a indicação do cargo ao seu oferecimento para a organização do Instituto (Franco, 1888). Ambas as propostas apontavam a chácara pertencente aos herdeiros do visconde de Bom Retiro, próxima à Estação do Engenho Novo e que estava por ele arrendada, como local próprio para a instalação do Instituto. A cessão do prédio a ser construído para esse fim seria por dez anos, correspondente ao prazo em que a chácara estaria arrendada em seu nome. Apesar da formulação proposta e de iniciada a construção do prédio que abrigaria o Instituto, Pedro Affonso acabou não instalando o Instituto na Chácara de Bom Retiro. ${ }^{17}$ Manteve a produção da vacina nas dependências da Santa Casa até 1894 e recebeu do governo republicano, a partir de maio de 1890, o subsídio solicitado em 1888.

O espaço conquistado por Pedro Affonso, principalmente no interior das instâncias governamentais, com a introdução da vacina animal no Brasil, permitiu-lhe criar, em 1894, o Instituto Vacínico e dirigir a produção da vacina animal até 1920, apesar da conjuntura adversa simbolizada pela ascensão de Oswaldo Cruz na saúde pública brasileira.

\section{Notas}

1 O conceito de Estado aqui utilizado não o percebe como um conjunto de 'aparelhos' que determinam a ordem por meio da dominação e, sim, como um espaço de relação político-ideológica. A vinculação da Junta Vacínica com o Estado não se estabelecia apenas por uma relação burocrática, mas também responde a uma lógica mais ampla de cunho ideológico, que permeará as ações no campo social, acompanhando a consolidação desse Estado em processo de construção. Para esse entendimento, estamos utilizando a proposta de Estado em Gramsci: BuciGlucksmann (1980). 
2 Sobre as transformações socioeconômicas que caracterizaram a mudança de Brasil Colônia a Império existe vasta bibliografia. Citamos, aqui, Gorender (1978).

3 Sobre a estruturação da cidade do Rio de Janeiro no século XIX e o processo de remodelação vivido pela capital no início do século XX, contamos com um importante trabalho de Benchimol (1990).

4 Depoimento-testemunho do intendente-geral de Polícia sobre o conteúdo do documento de criação da Junta em face do extravio do original - Acervo do Arquivo Nacional.

5 A Fisicatura tinha ação de fiscalização e não de intervenção propriamente médica, necessitando do órgão de polícia para o seu exercício fiscalizador. Posteriormente, a complexificação da estrutura dos serviços de saúde e a incorporação ideológica do 'controle' incluída no serviço médico dispensariam a vinculação da Junta com a Intendência-Geral de Polícia, sendo absorvido o papel da Polícia nesses serviços.

6 Sobre a organização dos médicos no século XIX e a participação da Academia de Medicina e das faculdades de medicina na condução política, utilizamos trabalhos como os de Edler, Ferreira e Santos (1991) e Kury (1990).

7 Acervo do Arquivo Nacional - Documento enviado ao ministro e secretário de Estado dos Negócios do Império pelo diretor da Faculdade em 8 de junho de 1839.

8 Documento encaminhado a Bernardo Pereira de Vasconcelos em 21 de março de 1839.

9 A preocupação com a organização dos serviços de vacinação partiu da própria direção da Junta Vacínica, que, em 1842, enviou ao ministro e secretário dos Negócios do Império, anexa ao mapa de vacinação e relatório de atividades do órgão, uma proposta de regulamento ao qual ficaria a instituição subordinada até que se estabelecesse um Regulamento Geral. Na realidade, tratava-se apenas de normas de funcionamento interno sobre o número de funcionários e suas atribuições (Acervo do Arquivo Nacional).

10 Algumas das propostas indicadas compõem o Acervo do Arquivo Nacional, outras foram reproduzidas em trabalhos sobre a varíola no Brasil, como, por exemplo, os de autoria de médicos de destaque como Plácido Barbosa e Pedro Affonso Franco.

11 As referências ao aumento de casos de varíola estão contidas nos documentos oficiais e cartas que compõem o Acervo do Arquivo Nacional.

12 A Santa Casa, até então, vinha dedicando-se à assistência médica à população desassistida desses serviços, assumindo o Estado, diretamente, a Higiene Pública. Sua atuação assentava-se na filantropia, e recebia para isso apoio estatal no que diz respeito, principalmente, a recursos financeiros por meio de subsídios, concessão de loterias, taxas alfandegárias, isenção de impostos e outros meios indiretos. A filantropia exercida pela Santa Casa concorria entre as instituições de ação filantrópica como grande expressão de prestígio político para aqueles que a ela se vinculavam (Vieira, 1982; Coimbra, 1986).

13 A partir de 1908, justificado pela partilha dos bens da família, o barão de Pedro Affonso passou a cobrar do governo municipal aluguel pelas propriedades ocupadas pela instalação do Instituto Vacínico. Com isso, a esposa passou a receber 3/4 do aluguel do prédio da rua do Catete, e Pedro Affonso o restante. Uma das filhas ficou recebendo a importância relativa ao aluguel das cocheiras (Instituto Vacínico Municipal. Relatório de Atividades, 1913). 
14 Assistiu o presidente quando este se submeteu a uma cirurgia renal em 1896. Dirigiu a equipe médica, tendo como auxiliares Toledo Dodsworth e Paulino Werneck. A cirurgia e a recuperação do presidente foram acompanhadas também por Barata Ribeiro.

15 O relatório foi reproduzido na íntegra no texto "Varíola e vacinas: da vacinação animal no Brasil", escrito por Pedro Affonso em 1888.

16 Em razão do Relatório da Comissão, Pedro Affonso passou a aplicar também a vacina humanizada, procurando, no entanto, convencer a população das qualidades da vacina animal.

17 A documentação por nós localizada não explicita por que motivo a chácara não foi utilizada para a organização do Instituto, apenas refere-se à sua permanência temporária junto à Santa Casa. Quanto à nomeação de Henrique Dodsworth, esta também não ocorreu, permanecendo Pedro Affonso à frente dos serviços de vacinação. Dodsworth incorporou-se ao Instituto Municipal, que foi mais tarde criado pelo próprio Pedro Affonso. 